\title{
Blood pressure in normal pregnancies from Mexico City
}

\author{
Presión arterial en embarazos normales de la Ciudad de México \\ Héctor Oviedo-Cruz ${ }^{1 *}$ and Marco A. Cortés-Martínez ${ }^{2}$ \\ ${ }^{1}$ Department of Maternal-Fetal Medicine, Centro Médico para la Atención Fetal Especializada; ${ }^{2}$ Department of Biochemistry and Quality, Laboratorio \\ CEMAFE S.A. de C.V., Mexico City, Mexico
}

\begin{abstract}
Objective: To determine the normal blood pressure (BP) in pregnancy, Mexico City. Methods: A cross-sectional observational study was carried out of BP on singleton normal pregnancies in Mexico City. Measurements followed a standardised methodology using automated electronic devices. Reference values of systolic (SBP), diastolic (DBP) and mean arterial pressure (MAP) were constructed. Maternal and gestation characteristics effects on $B P$ were tested. The reference ranges of $B P$ were adjusted for significant variables. Results: On 1,056 women of 33 years old mean age and $160.0 \mathrm{~cm}$ mean height, 1,915 measurements were made between 5 and 41 weeks of gestational age (GA) with $65.0 \mathrm{~kg}$ of mean weight. The median BP throughout pregnancy was 102.7/67.2 \pm 9.3/7.4 SD mmHg, and 79.0 $\pm 7.4 S D \mathrm{mmHg}$ the MAP. BP had a quadratic relationship with GA, being the lowest in $2^{\text {nd }}$ trimester. $S B P$ and DBP had a $r=0.71$ linear correlation. Maternal weight had the most significant effect on SBP and MAP; height, on DBP. Maternal age, ethnic origin, parity, tobacco habit and family history had differential effects on BP. Gestation had no significant effect on SBP multivariate model. Conclusions: BP resulted lower than conventional standard for pregnant women. Diagnostic criteria for hypertension in pregnancy must be revised; reference values can be adjusted by maternal and gestation characteristics.
\end{abstract}

Key words: Blood pressure. Pregnancy. Reference values. Pre-eclampsia. Mexico.

\section{Resumen}

Objetivo: Determinar la presión arterial (PA) normal en embarazadas en la Ciudad de México. Método: Estudio transversal descriptivo de la PA en embarazos normales de feto único en la Ciudad de México. Las mediciones siguieron un método estandarizado con uso de dispositivos electrónicos automatizados. Se construyeron valores de referencia de las presiones sistólica (PS), diastólica (PD) y arterial media (PAM). Se probaron los efectos de las características maternas y de la gestación sobre la PA. Los intervalos de referencia de la PA se ajustaron para las variables significativas. Resultados: En 1,056 mujeres con edad media de 33 años y $160 \mathrm{~cm}$ medios de estatura se realizaron 1,915 mediciones entre las 5 y 41 semanas de edad gestacional (EG) con peso medio de $65 \mathrm{~kg}$. La PA durante el embarazo fue de 102.7/67.2 \pm 9.3/7.4 DE mmHg y 79.0 \pm 7.4 DE mmHg la PAM. La PA tuvo una relación cuadrática con la EG, la más baja en el segundo trimestre. La PS y la $P D$ mostraron una correlación lineal $(r=0.71)$. El peso materno tuvo el efecto más significativo sobre PS y PAM; la estatura sobre la PD. La edad, etnia, paridad, consumo de tabaco y antecedente familiar ejercieron efectos diferentes en cada PA. La gestación no tuvo efecto significativo en el modelo multivariado de la PS. Conclusiones: La PA se halló por debajo de la norma convencional en embarazadas. Los criterios diagnósticos para hipertensión en el embarazo deben revisarse; los valores de referencia pueden ajustarse a características maternas y gestacionales.

Palabras clave: Presión arterial. Embarazo. Valores de referencia. Preeclampsia. México.

Correspondence:

*Héctor Oviedo-Cruz

E-mail: HectorOC@ @emafe.org.mx
Available online: $20-10-2021$ Arch Cardiol Mex (Eng). 2021;91(3):256-265 www.archivoscardiologia.com 2604-7063 / @ 2020 Instituto Nacional de Cardiología Ignacio Chávez. Published by Permanyer. This is an open access article under the CC BY-NC-ND license (http://creativecommons.org/licenses/by-nc-nd/4.0/). 


\section{Introduction}

Hypertension in pregnancy is defined as a systolic blood pressure (SBP) $\geq 140 \mathrm{mmHg}$, a diastolic blood pressure $(\mathrm{DBP}) \geq 90 \mathrm{mmHg}$, or both on two occasions, at least four hours apart ${ }^{1-4}$. This has been the standard of care for many years ${ }^{5}$. In non-pregnant population, the American College of Cardiology (ACC) has recently changed the definition of hypertension itself and endorsed lower thresholds with the purpose to reduce long-term cardiovascular morbidity ${ }^{6}$. The application of these lower intervals in the pregnant population has enabled better detection of maternal and perinatal adverse outcomes ${ }^{7,8}$.

On the other hand, the physiological changes in blood pressure during pregnancy ${ }^{9}$ have only recently been taken into account to generate reference ranges for assessing of pregnant women ${ }^{10}$. However, gestational age-dependent thresholds are not considered in clinical practice guidelines ${ }^{11}$.

Furthermore, one study described the differential effects of maternal characteristics and medical history on mean arterial pressure (MAP) in all three trimesters of pregnancy ${ }^{12}$.

The aim of this study was to generate blood pressure reference values during pregnancy, adjusted for specific maternal characteristics of the population.

\section{Materials and methods}

\section{Study population}

A cross-sectional study was carried out in singleton pregnancies of an intruterine live fetus, from spontaneous conception, and normal at the time of regular fetal ultrasound at a medical center and maternal-fetal medicine laboratory of Mexico City; inclusion of pregnant women who gave their consent to participate was consecutive. Healthy women of any ethnic origin were included; patients with chronic hypertension, diabetes, systemic lupus erythematosus, antiphospholipid syndrome or other diseases were not included, even if these comorbidities did not represent a cardiovascular risk. Pregnancies with fetal chromosomal, structural, or intrauterine growth abnormalities were excluded. Multiple pregnancies were not included because differences have been documented in them for blood pressure ${ }^{13}$ and cardiac function ${ }^{14}$; this is the subject for another research. The study was approved by the scientific and bioethics committees of the center, with adherence to the Declaration of Helsinki of the World Medical Association for medical research on human subjects.

\section{Patient characteristics}

Clinical characteristics were obtained using a self-administered questionnaire, verified by medical interview, and included maternal age, ethnicity (Caucasian/Hispanic, Afro-Caribbean, South Asian, East Asian or other/ mixed), smoking during pregnancy (smoker, never smoked or quit smoking), family history of preeclampsia in the mother or sister of the patient (yes or no) and obstetric history including parity (parity or nulliparity if there were no previous pregnancies of $\geq 24$ weeks of gestation) and previous pregnancy with pre-eclampsia (yes or no); these operational definitions are those used by the Fetal Medicine Foundation ${ }^{15}$ (note that the "nulliparous" category is not equal to "first pregnancy"; abortions and $<24$-week deliveries have no operational interest).

Maternal weight and height were obtained with calibrated analog standard clinical scale and stadiometer. The age of gestation was established by ultrasound or date of last menstruation period corroborated by ultrasound.

\section{Standardized method for measuring blood pressure in pregnancy}

In accordance with the international recommendations $^{11}$ developed by the Fetal Medicine Foundation ${ }^{12,16-18}$ and recently adopted by the International Federation of Gynecology and Obstetrics ${ }^{19}$, the use of automated electronic devices is specified to avoid human bias and interchangeability by auscultation ${ }^{20}$. Instead of establishing a fixed number of readings, those that are necessary to obtain the baseline status of the pregnant woman are taken; one study reported that there are cases that require four or more readings ${ }^{18}$; measurements are simultaneous in both arms to avoid bias resulting from differences between both arms $^{21}$, which are described even in normal pregnancies ${ }^{22}$. The mandatory modification for this study was the use in all pregnant women of a unique medium-size cuff $(22-32 \mathrm{~cm})$ provided with each device, placed at brachial circumference margin, which is why it was not measured in this study; cuffs of other calibers for such devices are not available in the local market.

Blood pressure readings were performed after a five-minute rest period in the sitting position and with the pregnant woman's arms at the heart level. At the study site, there are chairs for that purpose, with 
adjustable armrests on both sides and backrest; known recommendations on the conditions and position for the readings were observed ${ }^{11}$. At least three consecutive brachial measurements were performed in both arms at one-minute intervals until the difference between systolic pressure readings was $\leq 10 \mathrm{mmHg}$ and $\leq 6 \mathrm{mmHg}$ for diastolic pressure; this criterion defines the baseline status of the pregnant woman. The automated electronic devices were of the same model throughout the study and met the calibration requirement. Two identical devices were used for each patient to simultaneously measure in both arms. MAP for each measurement and on each arm was calculated based on the known formula DBP + (SBP-DBP)/3. The study MAP results from the average of the last two stable measurements ${ }^{16}$. In this work, systolic (SBP) and diastolic (DBP) blood pressures were added for analysis.

The automated electronic device used in this study was HEM-7121 blood pressure monitor (Omron ${ }^{\circledR}$, Japan), which meets FDA's $510(\mathrm{k})$ requirement.

Medical, paramedical, and nursing staff in charge of the readings received training for the use of the electronic devices, on the standardized protocol, and they were supervised during the study.

\section{Statistical analysis}

Descriptive statistics were applied for SBP, DBP and MAP global distribution during pregnancy and to generate general equations. The reference intervals per week of gestation for SBP, DBP and MAP were developed in a form similar to that published by other authors ${ }^{10,18}$ following the Royston and Wright method ${ }^{23}$. The multiples of the median (MoM) corrected by gestation and maternal weight were calculated as usual ${ }^{24}$. The curves were adjusted to polynomial equations by least-squares regression; the model was selected on the basis of goodness-of-fit indices, residual analysis, inspection, and simplicity.

The effects of maternal and pregnancy characteristics on BP were assessed using multiple linear regression; the analysis was stepwise to detect confounding and interaction effects. The best model for each BP was selected based on performance indices, clinical consistency and residual analysis. The model for calculating the multivariate percentile is based on the modified Royston and Wright method ${ }^{23}$ : the median was obtained from all the variables included in the final model and not only by gestational age; the consistency of the model was analyzed on each independent variable.
Table 1. Population sample demographic characteristics

\begin{tabular}{|c|c|c|}
\hline Variable & \multicolumn{2}{|c|}{ Value } \\
\hline $\begin{array}{l}\text { Maternal age in years, median } \\
\text { (IOR) }\end{array}$ & 33.0 & $(29.0 ; 36.0)$ \\
\hline $\begin{array}{l}\text { Maternal weight in } \mathrm{kg} \text {, median } \\
\text { (IOR) }\end{array}$ & 65.0 & $(58.4 ; 73)$ \\
\hline $\begin{array}{l}\text { Maternal height in } \mathrm{cm} \text {, median } \\
\text { (IOR) }\end{array}$ & 160.0 & $(156 ; 164)$ \\
\hline Body mass index, median (IQR) & 25.3 & $(23 ; 28.1)$ \\
\hline $\begin{array}{l}\text { Ethnicity } \\
\text { Caucasian/Hispanic, n (\%) } \\
\text { Afro-Caribbean, n (\%) } \\
\text { South Asian, n (\%) } \\
\text { East Asian, n (\%) } \\
\text { Other, mixed, n (\%) }\end{array}$ & $\begin{array}{c}1601 \\
3 \\
1 \\
24 \\
286\end{array}$ & $\begin{array}{l}(83.6 \%) \\
(0.2 \%) \\
(0.1 \%) \\
(1.3 \%) \\
(14.9 \%)\end{array}$ \\
\hline $\begin{array}{l}\text { Parity } \\
\text { Nulliparous, } \mathrm{n}(\%) \\
\text { Parity without pre-eclampsia, } \\
\mathrm{n}(\%) \\
\text { Parity with previous } \\
\text { pre-eclampsia, } \mathrm{n}(\%)\end{array}$ & $\begin{array}{c}1,041 \\
843 \\
31\end{array}$ & $\begin{array}{l}(54.4 \%) \\
(44.0 \%) \\
(1.6 \%)\end{array}$ \\
\hline $\begin{array}{l}\text { Smoking habit } \\
\text { Smoker, n (\%) } \\
\text { Quit smoking, n (\%) } \\
\text { Non-smoker, n (\%) }\end{array}$ & $\begin{array}{c}8 \\
224 \\
1,680\end{array}$ & $\begin{array}{c}(0.4 \%) \\
(11.7 \%) \\
(87.7 \%)\end{array}$ \\
\hline $\begin{array}{l}\text { Family history of pre-eclampsia, } \\
n(\%)\end{array}$ & 56 & $(2.9 \%)$ \\
\hline
\end{tabular}

The normality assumptions that required formal corroboration were evaluated with the Shapiro-Wilk test ${ }^{25-26}$; based on the result, parametric or non-parametric statistics were applied, or the variables were transformed before their analysis. For the multivariate analysis, assumptions of similar variances, linear relationship and collinearity were additionally corroborated by transforming the variable if necessary. The level of significance was $\alpha=0.05$ for $p$-value statistical tests.

The database was created using the Astraia ${ }^{\circledR}$ (Germany) and Excel ${ }^{\circledR}$ programs (USA); DOI: 10.6084/m9. figshare.12264152. Statistical analysis was performed in Excel $^{\circledR}$ (USA) and MATLAB ${ }^{\circledR}$ (USA) programs, with their due licenses.

\section{Results}

The population sample was recruited between January 2017 and July 2018; it comprised 1,056 women who met all inclusion criteria. A total of 1,915 measurements between 5 and 41 weeks of gestation were obtained; the characteristics of the study population, which did not include indigenous population, are presented in table 1. 


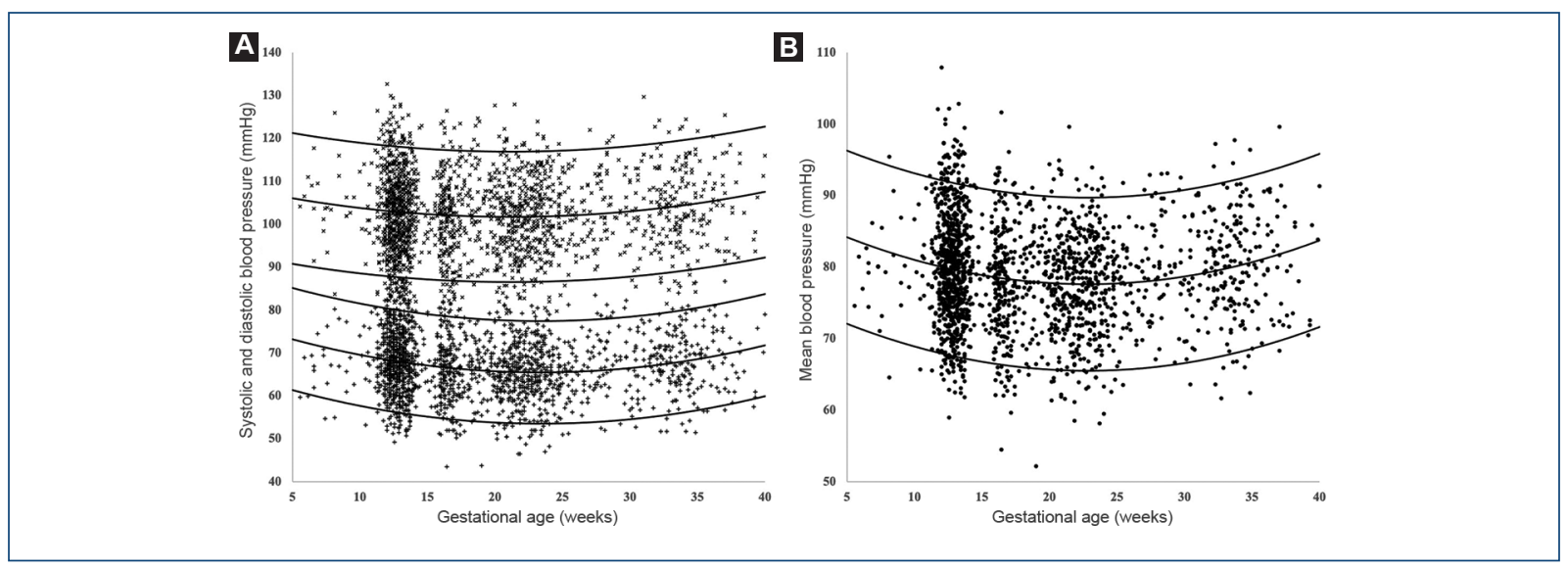

Figure 1. Scatter plot. A: Systolic (x) with diastolic (+) blood pressure. B: Mean arterial pressure vs. gestational age in this population. Calculated medians are shown, with their respective $5^{\text {th }}$ and $95^{\text {th }}$ percentiles.

In 416 pregnancies $(21.7 \%)$, four or more readings were required to obtain this study's operative definition of pregnant woman baseline status.

Global blood pressure had a normal distribution and is presented in table 2. The formula to calculate the crude percentile of blood pressure during pregnancy follows the Gaussian equation (e.g., $5^{\text {th }}$ and $95^{\text {th }}$ percentiles, table 2).

Gestational age showed a U-shaped quadratic relationship with blood pressure, which was lower in the second trimester. The nomograms by weeks of gestation are shown in figure 1 , and the reference intervals are listed in table 3 . The model for the percentile of each blood pressure by gestational age and for MoMs corrected by maternal weight is presented in table 4.

For the multivariate analysis, three registries of African and one of South Asian ethnic origin were excluded due to insufficient numbers. The relationship between SBP and DBP was of the linear type, with a correlation $r=0.71$ (Pearson, $p<0.001$ ), constant of 42.8 (95\% Cl: $40.1,45.5)$ and coefficient of $0.89(95 \%$ Cl: $0.85,0.93)$. The correlation $r$ between SBP and DBP was lower than the collinearity critical value of 0.8. Multivariate models were developed for SBP, DBP and MAP, including DBP in the SBP model and vice versa; only the age of gestation required quadratic transformation, centered at the lowest critical value of each blood pressure.

The coefficients of each multivariate final model and their statistics are presented in tables 5 to 7 for SBP, DBP and MAP, respectively. Confounding effects were
Table 2. General blood pressure $(\mathrm{mmHg})$ during pregnancy

\begin{tabular}{|l|c|c|c|}
\hline Variable & Value & $\mathbf{p 5}$ & $\mathbf{p 9 5}$ \\
\hline $\begin{array}{l}\text { Systolic blood } \\
\text { pressure, mean } \pm \text { SD }\end{array}$ & $102.7 \pm 9.30$ & 87.4 & 118.0 \\
\hline $\begin{array}{l}\text { Diastolic blood } \\
\text { pressure, mean } \pm \text { SD }\end{array}$ & $67.2 \pm 7.38$ & 55.1 & 79.3 \\
\hline $\begin{array}{l}\text { Mean blood } \\
\text { pressure, mean } \pm \text { SD }\end{array}$ & $79.0 \pm 7.44$ & 66.8 & 91.3 \\
\hline
\end{tabular}

identified during the stepwise process of each model; they are discussed below (intermediate coefficients are not shown).

DBP was SBP main determinant by nullifying the effect of pregnancy on it and had a confounding effect on maternal characteristics such as weight, age, height, ethnicity, parity, quit smoking and family history of pre-eclampsia. Maternal weight, which was the second SBP determinant (T-values), had a confounding effect on gestational age and maternal characteristics, except for height. In the final model, gestational age $(F=0.4566$, $p=0.499$ ), ethnicity (other, mixed; $F=0.3798, p=$ 0.538; and East Asian; $F=0.8114, p=0.368$ ) were excluded.

SBP, DBP main determinant, had a confounding effect on all maternal and gestational variables. The variable with the largest statistical effect on MAP was maternal weight, and no confounding variables were found; conversely, maternal weight had a confounding effect on 
Arch Cardiol Mex (Eng). 2021;91(3)

Table 3. Blood pressure reference ranges by gestational age

\begin{tabular}{|c|c|c|c|c|c|c|c|c|c|}
\hline \multirow{2}{*}{$\begin{array}{l}\text { Gestational } \\
\text { week }\end{array}$} & \multicolumn{3}{|c|}{ SBP } & \multicolumn{3}{|c|}{ DBP } & \multicolumn{3}{|c|}{ MAP } \\
\hline & p5 & Median & p95 & p5 & Median & p95 & p5 & Median & p95 \\
\hline 5 & 90.9 & 106.1 & 121.3 & 61.4 & 73.3 & 85.2 & 72.1 & 84.2 & 96.3 \\
\hline 6 & 90.3 & 105.6 & 120.8 & 60.5 & 72.5 & 84.4 & 71.4 & 83.5 & 95.6 \\
\hline 7 & 89.9 & 105.1 & 120.3 & 59.8 & 71.7 & 83.6 & 70.7 & 82.8 & 94.9 \\
\hline 8 & 89.4 & 104.6 & 119.9 & 59.0 & 71.0 & 82.9 & 70.1 & 82.2 & 94.3 \\
\hline 9 & 89.0 & 104.2 & 119.4 & 58.3 & 70.3 & 82.2 & 69.5 & 81.6 & 93.7 \\
\hline 10 & 88.6 & 103.8 & 119.1 & 57.7 & 69.6 & 81.6 & 68.9 & 81.0 & 93.1 \\
\hline 11 & 88.3 & 103.5 & 118.7 & 57.1 & 69.1 & 81.0 & 68.4 & 80.5 & 92.6 \\
\hline 12 & 88.0 & 103.2 & 118.4 & 56.6 & 68.5 & 80.4 & 68.0 & 80.1 & 92.2 \\
\hline 13 & 87.7 & 102.9 & 118.1 & 56.1 & 68.0 & 79.9 & 67.5 & 79.6 & 91.7 \\
\hline 14 & 87.4 & 102.6 & 117.9 & 55.6 & 67.5 & 79.5 & 67.2 & 79.2 & 91.3 \\
\hline 15 & 87.2 & 102.4 & 117.6 & 55.2 & 67.1 & 79.1 & 66.8 & 78.9 & 91.0 \\
\hline 16 & 87.0 & 102.2 & 117.5 & 54.8 & 66.8 & 78.7 & 66.5 & 78.6 & 90.7 \\
\hline 17 & 86.9 & 102.1 & 117.3 & 54.5 & 66.5 & 78.4 & 66.2 & 78.3 & 90.4 \\
\hline 18 & 86.7 & 102.0 & 117.2 & 54.2 & 66.2 & 78.1 & 66.0 & 78.1 & 90.2 \\
\hline 19 & 86.7 & 101.9 & 117.1 & 54.0 & 66.0 & 77.9 & 65.8 & 77.9 & 90.0 \\
\hline 20 & 86.6 & 101.8 & 117.0 & 53.8 & 65.8 & 77.7 & 65.7 & 77.8 & 89.9 \\
\hline 21 & 86.6 & 101.8 & 117.0 & 53.7 & 65.7 & 77.6 & 65.6 & 77.7 & 89.8 \\
\hline 22 & 86.6 & 101.8 & 117.0 & 53.6 & 65.6 & 77.5 & 65.6 & 77.6 & 89.7 \\
\hline 23 & 86.6 & 101.8 & 117.1 & 53.6 & 65.5 & 77.5 & 65.5 & 77.6 & 89.7 \\
\hline 24 & 86.7 & 101.9 & 117.1 & 53.6 & 65.5 & 77.5 & 65.6 & 77.7 & 89.8 \\
\hline 25 & 86.8 & 102.0 & 117.2 & 53.6 & 65.6 & 77.5 & 65.6 & 77.7 & 89.8 \\
\hline 26 & 87.0 & 102.2 & 117.4 & 53.7 & 65.7 & 77.6 & 65.7 & 77.8 & 89.9 \\
\hline 27 & 87.1 & 102.3 & 117.6 & 53.9 & 65.8 & 77.8 & 65.9 & 78.0 & 90.1 \\
\hline 28 & 87.3 & 102.5 & 117.8 & 54.1 & 66.0 & 78.0 & 66.1 & 78.2 & 90.3 \\
\hline 29 & 87.6 & 102.8 & 118.0 & 54.3 & 66.3 & 78.2 & 66.3 & 78.4 & 90.5 \\
\hline 30 & 87.8 & 103.1 & 118.3 & 54.6 & 66.5 & 78.5 & 66.6 & 78.7 & 90.8 \\
\hline 31 & 88.1 & 103.4 & 118.6 & 54.9 & 66.9 & 78.8 & 66.9 & 79.0 & 91.1 \\
\hline 32 & 88.5 & 103.7 & 118.9 & 55.3 & 67.2 & 79.2 & 67.3 & 79.4 & 91.5 \\
\hline 33 & 88.8 & 104.1 & 119.3 & 55.7 & 67.7 & 79.6 & 67.7 & 79.8 & 91.9 \\
\hline 34 & 89.2 & 104.5 & 119.7 & 56.2 & 68.1 & 80.1 & 68.1 & 80.2 & 92.3 \\
\hline 35 & 89.7 & 104.9 & 120.1 & 56.7 & 68.6 & 80.6 & 68.6 & 80.7 & 92.8 \\
\hline 36 & 90.2 & 105.4 & 120.6 & 57.2 & 69.2 & 81.1 & 69.2 & 81.3 & 93.3 \\
\hline 37 & 90.7 & 105.9 & 121.1 & 57.9 & 69.8 & 81.7 & 69.7 & 81.8 & 93.9 \\
\hline 38 & 91.2 & 106.4 & 121.6 & 58.5 & 70.4 & 82.4 & 70.3 & 82.4 & 94.5 \\
\hline 39 & 91.7 & 107.0 & 122.2 & 59.2 & 71.1 & 83.1 & 71.0 & 83.1 & 95.2 \\
\hline 40 & 92.3 & 107.6 & 122.8 & 59.9 & 71.9 & 83.8 & 71.7 & 83.8 & 95.9 \\
\hline
\end{tabular}


Table 4. Blood pressure model by gestational age and correction for weight

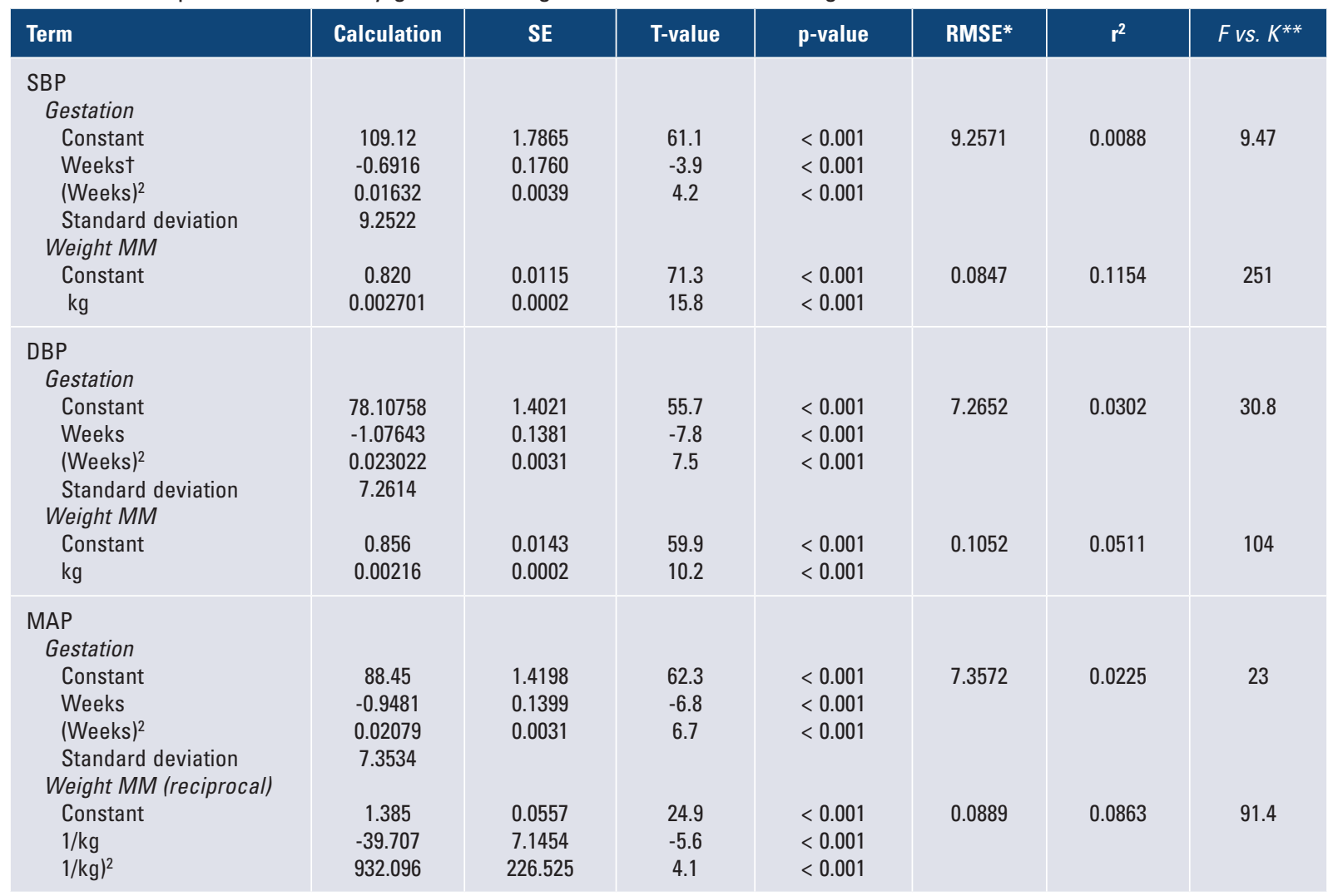

*Root mean square error.

$r^{2}=$ adjusted coefficient of determination for the polynomial equation.

${ }^{*}$ F-statistic vs. constant model: all with $\mathrm{p}$-value $<0.001$.

${ }^{\dagger} \mathrm{Gestational}$ age in weeks + days/7.

maternal age, ethnicity, previous pre-eclampsia, smoking, quit smoking, and family history of preeclampsia. Gestational age was the second variable in terms of statistical effect on MBP, was independent of maternal weight, and had a confounding effect on maternal age, height, and smoking. There was no confounding or interaction effect between maternal weight and gestational age. Ethnicity had a confounding effect on maternal height and family history of pre-eclampsia on the diverse and mixed ethnic group. In turn, parity was a confounding variable for maternal age, smoking and family history of pre-eclampsia. The only characteristic excluded from MAP final model was smoking $(F=0.1741, p=0.677)$.

From the residual analysis, a constant standard deviation was determined in each model to calculate the personalized percentile of each pressure; they are shown in their respective table. The models have been encoded on file, DOI: $10.6084 / \mathrm{m} 9$.figshare.12268328.

\section{Discussion}

SBP, DBP and MAP general distributions were below conventional standards with or without pregnancy ${ }^{1-4,11}$, similar to that described in non-pregnant women from a population different to this ${ }^{27}$. Of note, the "elevated blood pressure" threshold according to $\mathrm{ACC}^{6}$, $120 / 80 \mathrm{mmHg}$, is equivalent to the $97^{\text {th }}$ percentile both, in this population of pregnant women and in non-pregnant women of the referred study ${ }^{27}$; in addition, this $120 / 80 \mathrm{mmHg}$ threshold has been shown of value for predicting pre-eclampsia and other perinatal adverse outcomes in other studies ${ }^{7,8}$. Therefore, the diagnostic criteria for hypertension during pregnancy should be reviewed. This study proposes a statistical definition of normality; however, further longitudinal studies are required to satisfactorily answer this issue. 
Table 5. Multivariate model of systolic blood pressure during pregnancy

\begin{tabular}{|c|c|c|c|c|}
\hline Term & Calculation & SE & T-value & p-value \\
\hline $\begin{array}{l}\text { Expected mean value } \\
\text { Intersection } \\
\text { Diastolic pressure }\end{array}$ & $\begin{array}{c}18.7195 \\
1.1901\end{array}$ & $\begin{array}{l}9.3639 \\
0.1136\end{array}$ & $\begin{array}{c}2.0 \\
10.5\end{array}$ & $\begin{array}{l}0.046 \\
<0.001\end{array}$ \\
\hline $\begin{array}{l}\text { Maternal weight } \\
\text { Diastolic pressure:weight }\end{array}$ & $\begin{array}{l}0.5418 \\
-0.0054\end{array}$ & $\begin{array}{l}0.1182 \\
0.0017\end{array}$ & $\begin{array}{c}4.6 \\
-3.2\end{array}$ & $\begin{array}{c}<0.001 \\
0.001\end{array}$ \\
\hline Maternal age & 0.0359 & 0.0314 & 1.1 & 0.252 \\
\hline Maternal height & -0.0591 & 0.0359 & -1.6 & 0.100 \\
\hline $\begin{array}{l}\text { Parity† } \\
\text { Previous pre-eclampsia } \\
\text { Age:previous pre-eclampsia } \\
\text { Nulliparous } \\
\text { Height:nulliparous }\end{array}$ & $\begin{array}{c}20.1042 \\
-0.5302 \\
-15.8734 \\
0.1028\end{array}$ & $\begin{array}{l}7.8066 \\
0.2261 \\
7.3952 \\
0.0461\end{array}$ & $\begin{array}{c}2.6 \\
-2.3 \\
-2.1 \\
2.2\end{array}$ & $\begin{array}{l}0.010 \\
0.019 \\
0.032 \\
0.026\end{array}$ \\
\hline $\begin{array}{l}\text { Smoker } \\
\text { Weight:smoker }\end{array}$ & $\begin{array}{c}-35.6249 \\
0.5711\end{array}$ & $\begin{array}{c}14.2488 \\
0.2283\end{array}$ & $\begin{array}{l}-2.5 \\
2.5\end{array}$ & $\begin{array}{l}0.012 \\
0.012\end{array}$ \\
\hline $\begin{array}{l}\text { Quit smoking } \\
\text { Weight:quit smoking }\end{array}$ & $\begin{array}{l}6.2387 \\
-0.0937\end{array}$ & $\begin{array}{l}2.7398 \\
0.0404\end{array}$ & $\begin{array}{l}2.3 \\
-2.3\end{array}$ & $\begin{array}{l}0.023 \\
0.020\end{array}$ \\
\hline Family history of pre-eclampsia & 1.4381 & 0.8565 & 1.7 & 0.093 \\
\hline Standard deviation & 6.2315 & & & \\
\hline
\end{tabular}

${ }^{*}$ Root mean square error $=6.254$.

Squared r: 0.551, adjusted: 0.548 .

F-statistic vs. constant model: 166, p-value $<0.001$

${ }^{\dagger}$ Reference group: Caucasian/Hispanic, with parity, without pre-eclampsia.

MoM distribution was $1,000 \pm 0.061$ SD (Shapiro-Wilk $=0.9975, p=0.004$ ).

$Z$-score distribution was $0 \pm 1.0$ SD (Shapiro-Wilk $=0.9981, p=0.024$ ).

In this study, answering about the use of only three readings or as many as necessary is not foreseen; however, the fact that about one-fifth of the cases required four or more readings to obtain the operational definition here established for the pregnant woman baseline status, stands out. The significance of this finding could be the subject of another study.

The expected bias in blood pressure values due to the forced use of the unique cuff ${ }^{11}$ does not affect the validity of the models because adjustment for maternal weight could correct the brachial circumference effect ${ }^{28}$. This hypothesis should be the subject of another study.

The relationship of SBP and DBP with gestational age is here expressed by polynomial equations, similar as it was done in a meta-analysis ${ }^{10}$. The curves for DBP were almost identical between both studies, but not the SBP curves. This could be due to a consistent behavior throughout human gestation for DBP, but not for SBP, as explained by multivariate models, in which gestational age only maintains significant effects for DBP. Although SBP can be expressed by gestation, this relationship loses significance vs. maternal characteristics, which are its main determinants; this finding is consistent with another study, in which stroke volume was quantified throughout gestation, but was it was also particularly determined by maternal characteristics $^{29}$. Therefore, physiological changes of pregnancy, such as circulating volume, blood viscosity, heart rate and peripheral resistance, are especially reflected on DBP, which in turn explains approximately $50 \%$ of SBP variation (this quantification is unique in medical publications). When this effect is corrected, SBP then reflects the cardiovascular status of the woman as she became pregnant, not from population or ethnic origin, but medical history status: obstetric-gynecological and tobacco habit.

The quadratic relationship between MAP and gestation here described is similar to that published by the group that designed the original standardized method ${ }^{18}$ : it was lower in the second trimester, with constant variance throughout gestation. It is possible for blood to standardize the blood pressure measurement throughout pregnancy.

Similar to SBP and DBP, maternal characteristics, especially maternal weight, had a determinant effect on MAP, not secondary to nor resulting from correction for 
Table 6. Multivariate model of diastolic blood pressure during pregnancy

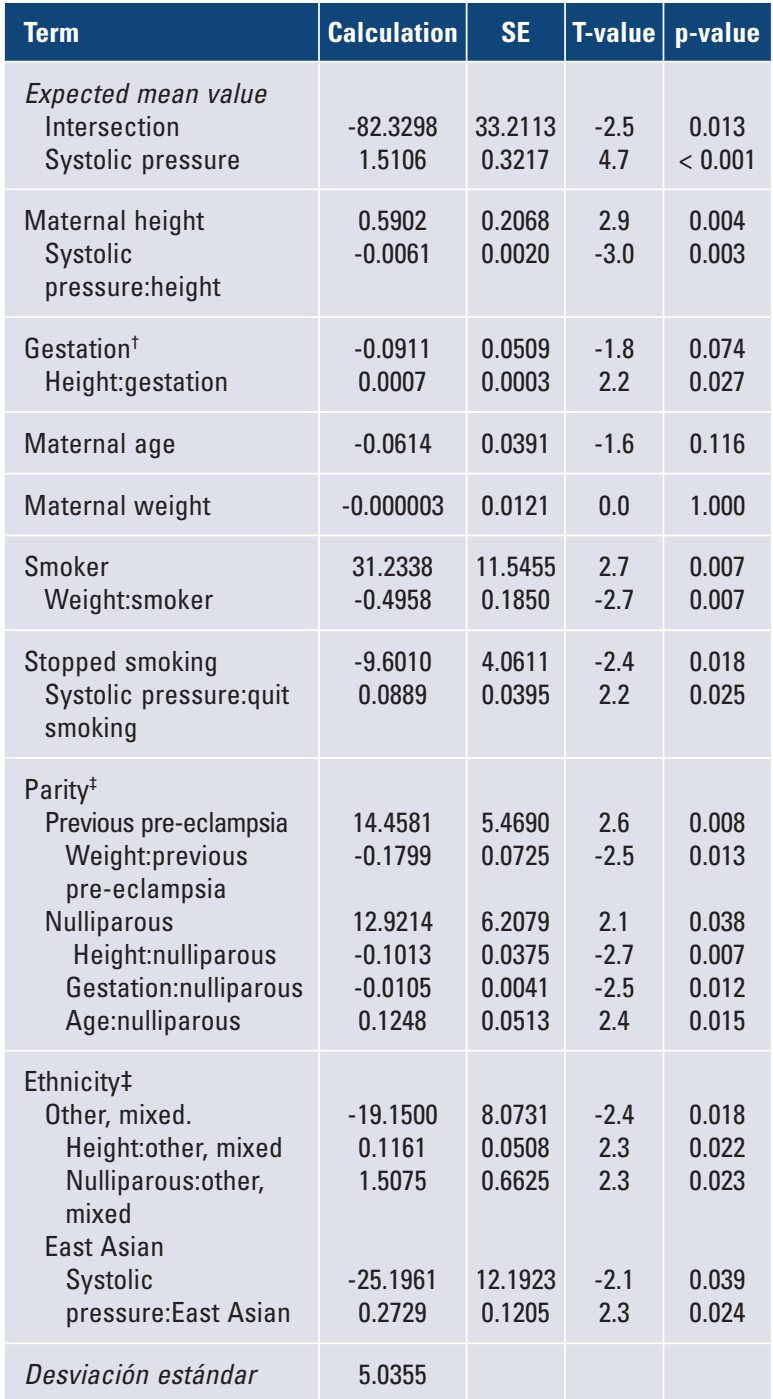

${ }^{*}$ Root mean square error $=5.065$.

Squared r: 0.533 , adjusted: 0.528

F-statistic vs. constant model: $98.1, \mathrm{p}$-value $<0.001$

${ }^{\dagger} \mathrm{Gestational}$ age in weeks, centered at $23 \mathrm{w} 3 \mathrm{~d}$ and with quadratic transformation. Gestation $=((\text { weeks }+ \text { days } / 7)-(23+3 / 7))^{2}$.

${ }^{\ddagger}$ Reference group: Caucasian/Hispanic, with parity, without pre-eclampsia.

MoM distribution was 1,000 \pm 0.075 SD (Shapiro-Wilk $=0.9990, p=0.356$ ).

$Z$-score distribution was $0 \pm 1.0 \mathrm{SD}$ (Shapiro-Wilk $=0.9985, \mathrm{p}=0.081$ ).

gestation, as it would be expected ${ }^{12,24}$. Although blood pressure reference ranges are generated according to gestation ${ }^{10,18}$, they must be corrected for maternal characteristics.

The effects of maternal characteristics on MAP described by other specialists ${ }^{12}$ have similarities with these findings; differences seem to come from population origin.

By design, it is not possible to differentiate between the physiological and the predictive effect of previous pre-eclampsia ${ }^{12}$, family history of pre-eclampsia ${ }^{12,15}$ and quit smoking ${ }^{30}$. Application of the models herein presented should be cross-sectional (diagnostic).

Future research will specify the above and other aspects, including the effect of the moment of smoking cessation $^{31}$, the extent of their application and usefulness in other groups such as diabetic and hypertensive women and the relationship of COVID-19 with pre-eclampsia ${ }^{32}$.

\section{Conclusions}

It is necessary to review the diagnostic criteria for hypertension during pregnancy. It is feasible to create standaradized reference ranges of blood pressure throughout pregnancy. Customization by maternal characteristics improves the model accuracy, because they are the main determinants the blood pressure in the pregnant woman. SBP could particularly represent the cardiovascular status as the woman becomes pregnant, whereas DBP could essentially reflect maternal adaptation to pregnancy.

\section{Funding}

None.

\section{Conflicts of interest}

The authors declare that they have no conflicts of interest.

\section{Ethical disclosures}

Protection of human and animal subjects. The authors declare that no experiments have been performed on humans or animals for this research.

Confidentiality of data. The authors declare that they have followed the protocols of their work center on the publication of patient data.

Right to privacy and informed consent. The authors declare that no patient data appear in this article 
Table 7. Multivariate model of mean blood pressure during pregnancy

\begin{tabular}{|c|c|c|c|c|}
\hline Term & Calculation & SE & T-value & p-value \\
\hline $\begin{array}{l}\text { Expected mean value } \\
\text { Intersection } \\
\text { Maternal weight }\end{array}$ & $\begin{array}{c}68.3306 \\
0.1898\end{array}$ & $\begin{array}{l}4.5517 \\
0.0155\end{array}$ & $\begin{array}{l}15.0 \\
12.3\end{array}$ & $\begin{array}{l}<0.001 \\
<0.001\end{array}$ \\
\hline Gestation $^{\dagger}$ & 0.0319 & 0.0044 & 7.2 & $<0.001$ \\
\hline Maternal age & -0.0495 & 0.0533 & -0.9 & 0.353 \\
\hline Maternal height & -0.0176 & 0.0279 & -0.6 & 0.527 \\
\hline $\begin{array}{l}\text { Parity }^{\ddagger} \\
\text { Previous pre-eclampsia } \\
\text { Height:previous pre-eclampsia } \\
\text { Nulliparous } \\
\text { Gestation:nulliparous } \\
\text { Age:nuliparous }\end{array}$ & $\begin{array}{l}62.3303 \\
-0.3593 \\
-4.5627 \\
-0.0185 \\
0.2047\end{array}$ & $\begin{array}{c}28.8721 \\
0.1803 \\
2.3367 \\
0.0058 \\
0.0699\end{array}$ & $\begin{array}{l}2.2 \\
-2.0 \\
-2.0 \\
-3.2 \\
2.9\end{array}$ & $\begin{array}{l}0.031 \\
0.046 \\
0.051 \\
0.002 \\
0.003\end{array}$ \\
\hline $\begin{array}{l}\text { Ethnicity } ¥ \\
\text { East Asian } \\
\text { Gestation:East Asian } \\
\text { Other, mixed } \\
\text { Nulliparous:other, mixed }\end{array}$ & $\begin{array}{c}-1.8627 \\
0.0669 \\
-1.4160 \\
2.3129\end{array}$ & $\begin{array}{l}2.4780 \\
0.0308 \\
0.6598 \\
0.8998\end{array}$ & $\begin{array}{c}-0.8 \\
2.2 \\
-2.1 \\
2.6\end{array}$ & $\begin{array}{l}0.452 \\
0.030 \\
0.032 \\
0.010\end{array}$ \\
\hline Quit smoking & -0.8939 & 0.4967 & -1.8 & 0.072 \\
\hline Family history of pre-eclampsia & 1.6792 & 0.9484 & 1.8 & 0.077 \\
\hline Standard deviation & 6.9064 & & & \\
\hline
\end{tabular}

${ }^{\dagger}$ Root mean square error $=6.934$.

Squared r: 0.139; adjusted: 0.133

F-statistic vs. constant model: $20.5, \mathrm{p}$-value $<0.001$

${ }^{\dagger} \mathrm{Gestational}$ age in weeks, centered at $22 \mathrm{w} 6 \mathrm{~d}$ and with quadratic transformation.

Gestation $=((\text { weeks }+ \text { days } / 7)-(22+6 / 7))^{2}$

${ }^{\ddagger}$ Reference group: Caucasian/Hispanic, with parity, without pre-eclampsia.

MoM distribution was $1.000 \pm 0.087$ SD (Shapiro-Wilk $=0.9985, p=0.091$ ).

$Z$-score distribution was $0 \pm 1.0 \mathrm{SD}$ (Shapiro-Wilk $=0.9985, \mathrm{p}=0.091$ )

\section{References}

1. Tranquilli AL, Dekker G, Magee L, Roberts J, Sibai BM, Steyn W, et al The classification, diagnosis and management of the hypertensive disorders of pregnancy: a revised statement from the ISSHP. Pregnancy Hypertens. 2014;4:97-104.

2. Lowe SA, Bowyer L, Lust K, McMahon LP, Morton M, North RA, et al. SOMANZ guidelines for the management of hypertensive disorders of pregnancy 2014. Aust NZJ Obstet Gynaecol. 2015;55:e1-e29.

3. ACOG Practice Bulletin No. 202: Gestational hypertension and preeclampsia. Obstet Gynecol. 2019;133:e1-e25.

4. Webster K, Fishburn S, Maresh M, Findlay SC, Chappell LC. Diagnosis and management of hypertension in pregnancy: summary of updated NICE guidance. BMJ. 2019;366:I5119.

5. Hypertension in pregnancy. Int J Gynecol Obstet. 1996;53:175-83.

6. Whelton PK, Carey RM, Aronow WS, Casey DE, Collins KJ, Dennison Himmelfarb C, et al. 2017 ACC/AHA/AAPA/ABC/ACPM/AGS/APhA/ ASH/ASPC/NMA/PCNA Guideline for the prevention, detection, evaluation, and management of high blood pressure in adults: a report of the American College of Cardiology/American Heart Association Task Force on Clinical Practice Guidelines. J Am Coll Cardiol. 2018;71:e127-e248

7. Sutton EF, Hauspurg A, Caritis SN, Powers RW, Catov JM. Maternal outcomes associated with lower range stage 1 hypertension. Obstet Gynecol. 2018;132:843-9.

8. Reddy M, Rolnik DL, Harris K, Li W, Mol BW, Da Silva Costa F, et al Challenging the definition of hypertension in pregnancy: a retrospective cohort study. Am J Obstet Gynecol. 2020;222:606.e1-.e21.

9. Wilson M, Morganti AA, Zervoudakis I, Letcher RL, Romney BM, Von Oeyon $\mathrm{P}$, et al. Blood pressure, the renin-aldosterone system and sex steroids throughout normal pregnancy. Am J Med. 1980;68:97-104.

10. Loerup L, Pullon RM, Birks J, Fleming S, Mackillop LH, Gerry S, et al. Trends of blood pressure and heart rate in normal pregnancies: a systematic review and meta-analysis. BMC Med. 2019;17:167.

11. Unger T, Borghi $C$, Charchar F, Khan NA, Poulter NR, Prabhakaran D, et al. 2020 International Society of Hypertension Global Hypertension Practice Guidelines. Hypertension. 2020;75:1334-57.

12. Wright A, Wright D, Ispas CA, Poon LC, Nicolaides KH. Mean arterial pressure in the three trimesters of pregnancy: effects of maternal characteristics and medical history. Ultrasound Obstet Gynecol. 2015;45:698-706.

13. Iwama N, Metoki H, Nishigori H, Mizuno S, Takahashi F, Tanaka K, et al. Blood pressure changes during twin pregnancies: the Japan Environment and Children's Study. J Hypertens. 2019;37:206-15.

14. Kuleva M, Youssef A, Maroni E, Contro E, Pilu G, Rizzo N, et al. Maternal cardiac function in normal twin pregnancy: a longitudinal study. UItrasound Obstet Gynecol. 2011;38:575-80.

15. Wright D, Syngelaki A, Akolekar R, Poon LC, Nicolaides KH. Competing risks model in screening for preeclampsia by maternal characteristics and medical history. Am J Obstet Gynecol. 2015;213:62 e1-e10.

16. Poon LCY, Zymeri NA, Zamprakou A, Syngelaki A, Nicolaides KH. Protocol for measurement of mean arterial pressure at 11-13 weeks' gestation. Fetal Diagn Ther. 2012;31:42-8.

17. Tayyar A, Krithinakis K, Wright A, Wright D, Nicolaides KH. Mean arterial pressure at 12, 22, 32 and 36 weeks' gestation in screening for pre-eclampsia. Ultrasound Obstet Gynecol. 2016;47:573-9.

18. Roberts L, Chaemsaithong P, Sahota DS, Nicolaides KH, Poon LCY. Protocol for measurement of mean arterial pressure at 10-40weeks' gestation. Pregnancy Hypertens. 2017;10:155-60.

19. Poon LC, Shennan A, Hyett JA, Kapur A, Hadar E, Divakar H, et al. The International Federation of Gynecology and Obstetrics (FIGO) initiative on pre-eclampsia: a pragmatic guide for first-trimester screening and prevention. Int J Gynecol Obstet. 2019;145:1-33. 
20. Oviedo-Cruz H R-MM, Cortés-Martínez MA. Intercambiabilidad entre el método por auscultación y por dispositivo electrónico automático de la presión arterial media en mujeres embarazadas sin hipertensión. Estudio piloto. Ginecol Obstet Mex. 2017;85:653-8.

21. Lane D, Beevers M, Barnes N, Bourne J, John A, Malins S, et al. Inter-arm differences in blood pressure: when are they clinically significant? J Hypertens. 2002;20:1089-95.

22. Poon L, Kametas N, Strobl I, Pachoumi C, Nicolaides K. Inter-arm blood pressure differences in pregnant women. BJOG. 2008; 115:1122-30

23. Royston $P$, Wright EM. How to construct 'normal ranges' for fetal variables. Ultrasound Obstet Gynecol. 1998;11:30-8.

24. Reynolds TM, Vranken G, Van Nueten J. Weight correction of MoM values: which method? J Clin Pathol. 2006:59:753-8.

25. Altman DG, Bland JM. Statistics notes: the normal distribution. BMJ. 1995;310:298.

26. Ghasemi A, Zahediasl S. Normality tests for statistical analysis: a guide for non-statisticians. Int J Endocrinol Metab. 2012;10:486-9.
27. Villarreal-García E, Villarreal-García LV. Presión arterial en población indígena tzotzil de Chiapas, México. Arch Cardiol Mex. 2018;88:381-5.

28. Ng CM, Badon SE, Dhivyalosini M, Hamid JJM, Rohana AJ, Teoh AN, et al. Associations of pre-pregnancy body mass index, middle-upper arm circumference, and gestational weight gain. Sex Reprod Healthc. 2019;20:60-5.

29. Vinayagam D, Thilaganathan B, Stirrup O, Mantovani E, Khalil A. Maternal hemodynamics in normal pregnancy: reference ranges and role of maternal characteristics. Ultrasound Obstet Gynecol. 2018;51:665-71.

30. Pipkin FB. Genetics of preeclampsia C. Smoking in moderate/severe preeclampsia worsens pregnancy outcome, but smoking cessation limits the damage. Hypertension. 2008;51:1042-6.

31. Wang X, Lee NL, Burstyn I. Maternal smoking and gestational hypertension: Heterogeneous effect by timing of the exposure. Pregnancy Hypertens. 2019;15:123-9.

32. Di Mascio D, Khalil A, Saccone G, Rizzo G, Buca D, Liberati M, et al. Outcome of coronavirus spectrum infections (SARS, MERS, COVID 1 -19) during pregnancy: a systematic review and meta-analysis. Am J Obstet Gynecol MFM. 2020;100107. 